\title{
Foliculitis decalvante: a propósito de un caso
}

\author{
Sergio A. Arbeláez-Eslait'; Koretta Esmeral-Atehortúa²; Sebastián Peluffo-Vergara
}

\section{RESUMEN}

La foliculitis decalvante es una variante rara de las alopecias cicatriciales primarias neutrofílicas, que cursa con áreas de alopecia cicatricial central y folículos en penacho rodeadas por pústulas foliculares recurrentes en la periferia; afectan principalmente el vértice y la región temporoparietal de la piel cabelluda.

Se discute el caso de un paciente de 20 años, quien presenta un cuadro clínico caracterizado por múltiples pústulas, con posterior evolución a placas alopécicas de tamaño y forma variable, de localización generalizada en toda la extensión de la piel cabelluda.

PALABRAS CLAVE: alopecia; foliculitis decalvante; fibrosis.

\section{FOLLICULITIS DECALVANS: A CASE REPORT}

\section{SUMMARY}

Introduction: Folliculitis decalvans is a rare variant of neutrophilic cicatricial alopecia that consist of areas of central scarring alopecia and tuft follicles surrounded by recurrent follicular pustules; they mainly affect the vertex and the temporo-parietal junction of the scalp.

The case of a 20-year-old patient is discussed, with a history of multiple pustules with subsequent evolution to alopecic plaques of variable size and shape, with a generalized location throughout the entire scalp.

KEY WORDS: Alopecia; Folliculitis decalvans; Fibrosis.

\footnotetext{
1. Médico interno, Hospital Universidad del Norte, Soledad, Atlántico, Colombia. ORCID https://orcid.org/oooo-0o03-2421-68612

2. Médico interno, Hospital Universidad del Norte, Soledad, Atlántico, Colombia. ORCID https://orcid.org/oooo-0001-9596-80463

3. Médico interno, Hospital Universidad del Norte, Soledad, Atlántico, Colombia. ORCID https://orcid.org/oooo-0003-2402-9476

Correspondencia: Koretta Esmeral Atehortúa; email: katehortua@uninorte.edu.co

Recibido: $16 / 02 / 20$; aceptado: $25 / 04 / 20$
}

Cómo citar: Arbeláez-Eslait SA, Atehortúa KE, Peluffo-Vergara S. Foliculitis decalvante: a propósito de un caso. Rev Asoc Colomb Dermatol. 2020;28(2): 169-175. DOI:

Financiación: ninguna, conflictos de interés: ninguno 


\section{INTRODUCCIÓN}

La foliculitis decalvante (FD) es un proceso patológico crónico y progresivo caracterizado por una inflamación del folículo pilosebáceo con secreción supurativa destructiva, que tras sanar deja una cicatriz atrófica $(1,2)$.

La prevalencia de la FD es del 10,7\%-11,2\% de las alopecias cicatriciales primarias. Afecta principalmente a adultos jóvenes de sexo masculino ${ }^{(3)}$.

Se ha relacionado la expresión de superantígenos y citotoxinas que se unen al complejo mayor de histocompatibilidad de clase II (CMH II); esto desencadena la activación del sistema de complemento y la respuesta inflamatoria, como base de la patogénesis de la enfer$\operatorname{medad}^{(4)}$.

Las manifestaciones clínicas incluyen pústulas foliculares, con base eritematosa, dolorosas y pruriginosas, que afectan con frecuencia el vértice y la región occipital de la piel cabelluda. Posteriormente sanan dejando una placa cicatricial irregular y atrófica con lesiones pustulosas activas en la periferia, con presencia de costras melicéricas ${ }^{(5)}$.

El diagnóstico de FD es principalmente clínico y se confirma con tricoscopía y biopsia del área afectada $(6,7)$.

A continuación, trataremos el reporte de caso de un paciente con lesiones pustulosas múltiples con posterior evolución a placas alopécicas en toda la extensión de la piel cabelluda.

\section{PRESENTACIÓN DEL CASO}

Se presenta el caso de un paciente masculino de 20 años, con cuadro clínico de 7 meses de evolución, caracterizado por la aparición de lesiones pustulosas múltiples de base eritematosa, dolorosas y pruriginosas con posterior evolución a placas alopécicas irregulares con lesiones activas en la periferia, de localización generalizada en la extensión de la piel cabelluda, con pobre respuesta al tratamiento antibiótico tópico con corticoides.

Paciente previamente sano, sin antecedentes médicos personales de importancia.
En el examen físico se evidencian múltiples placas alopécicas, con borde irregular constituido por lesiones activas de tipo pustuloso con costras melicéricas, localizadas de forma difusa en la piel cabelluda, principalmente en el vértice y la región temporoparietal izquierda (figura 1).

En la tricoscopía se evidenciaron múltiples tallos pilosos (5-15, aproximadamente) emergiendo de un único orificio folicular (pelos en penacho o "dolly hair”), escamas amarillentas, costras melicéricas y pústulas foliculares (figura 2).

En la biopsia del borde activo de la lesión, se observaron fragmentos de piel delgada con acantosis irregular, quiste rodeado por epitelio escamoso, con láminas de queratina en su centro, depósitos de material amorfo eosinofílico y hemorragia reciente (figura 3).

De acuerdo con los hallazgos clínicos y paraclínicos, el paciente fue diagnosticado con foliculitis decalvante.

Recibió terapia tópica con betametasona y ácido fusídico durante 30 días, sin evidenciar mejoría. Las lesiones progresaron en severidad y extensión pese al manejo instaurado, por lo cual se trató con terapia sistémica con doxiciclina en $100 \mathrm{mg}$, cada 8 horas, durante 3 meses. Posteriormente se evaluó la inactividad de las lesiones y se procedió a la extirpación escisional de las cicatrices más hipertróficas y a la infiltración intralesional de corticoides en las lesiones restantes.

\section{DISCUSIÓN}

La FD fue descrita por primera vez en 1888 por Quinquaud, como un proceso patológico crónico y progresivo caracterizado por una inflamación del folículo pilosebáceo con secreción supurativa destructiva, que tras sanar deja una cicatriz atrófica ${ }^{(1,2)}$.

La prevalencia de la FD es del 10,7\%-11,2\% de las alopecias cicatriciales primarias. Su edad de aparición es variable, con diagnóstico en los adultos jóvenes en su mayoría. Afecta con preferencia al sexo masculino ${ }^{(3)}$.

En cuanto a su etiología, se han visto implicadas bacterias Grampositivas, como Staphylococcus aureus (aislado en el 90\% de los casos) y Streptococcus pyogenes ( $<10 \%$ de casos). Fisiopatológicamente, se ha re- 

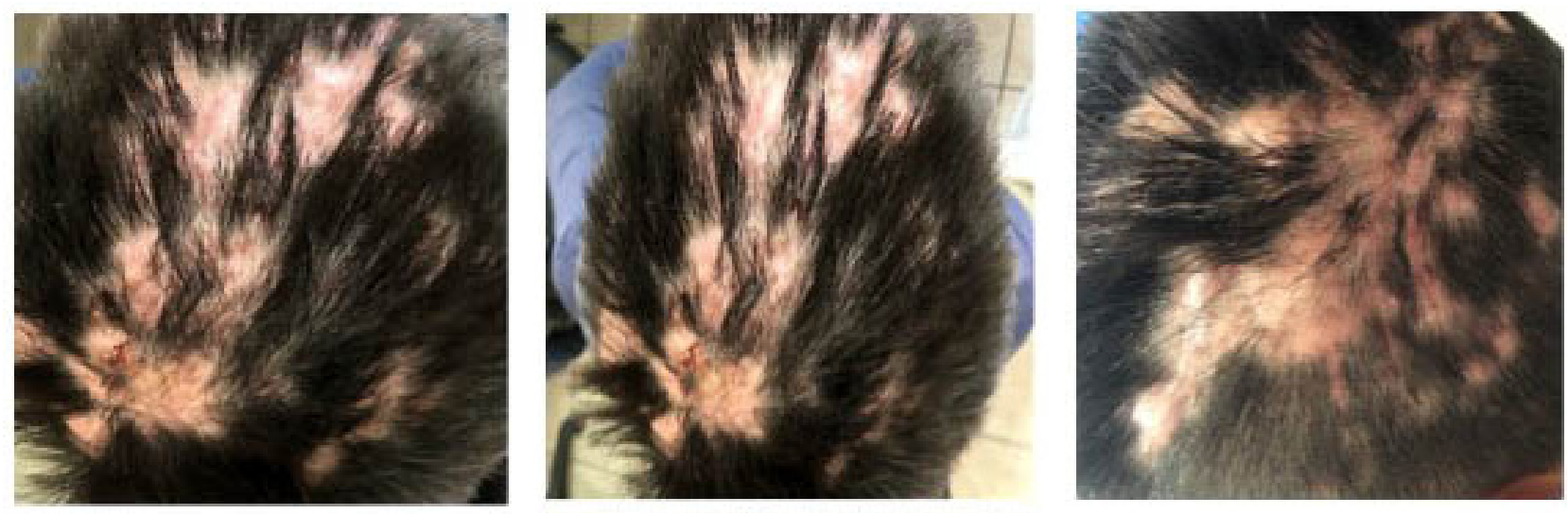

Figura 1. Placas eritematosas alopécicas, con bordes irregulares y presencia de pústulas en la periferia y costras melicéricas de localización difusa con predominio frontal y parietooccipital.

lacionado la expresión de superantígenos y citotoxinas que se unen al CMH II y desencadena la activación del sistema de complemento y la respuesta inflamatoria, como base de la patogénesis de la enfermedad ${ }^{(4)}$.

Las manifestaciones clínicas incluyen pústulas foliculares, con base eritematosa, dolorosas y pruriginosas, que afectan con frecuencia el vértice y la región occipital de la piel cabelluda. Posteriormente sanan dejando una placa cicatricial irregular y atrófica, con lesiones pustulosas activas en la periferia, con presencia de costras melicéricas ${ }^{(5)}$.

El diagnóstico de FD es principalmente clínico y se confirma con tricoscopía y biopsia del área afectada. En la tricoscopía se evidencia politriquia (emergencia de 5-20 pelos de un orificio folicular), eritema y descamación circundante. Para la biopsia se debe tomar muestra del borde activo de la lesión, donde se observará dilatación del infundíbulo, infiltrado neutrofílico y destrucción de las glándulas sebáceas circundantes.
En fases más crónicas de la entidad se evidencian linfocitos y células plasmáticas en la dermis y zonas granulomatosas perifoliculares ${ }^{(6,7)}$.

El tratamiento de la FD es complejo y se basa en la instauración de terapia antibiótica contra gérmenes Gram positivos, principalmente el $S$. aureus, ya que es el agente etiológico más frecuente en esta entidad ${ }^{\left({ }^{8}\right)}$.

El punto de partida en el manejo de la FD es la instauración de tratamiento tópico en los estadios iniciales, con antibióticos y corticoides. Los medicamentos de primera elección son: betametasona, hidrocortisona, mometasona, mupirocina al 2\%, clindamicina al $1 \% \mathrm{y}$ ácido fusídico al 2\% ${ }^{(8,12)}$.

La terapia farmacológica debe ser sistémica y en algunos casos se acompaña de tratamiento tópico para disminuir los síntomas inflamatorios. El tratamiento de elección es la rifampicina combinada con clindamicina. Esta terapia dual ha mostrado excelentes re- 


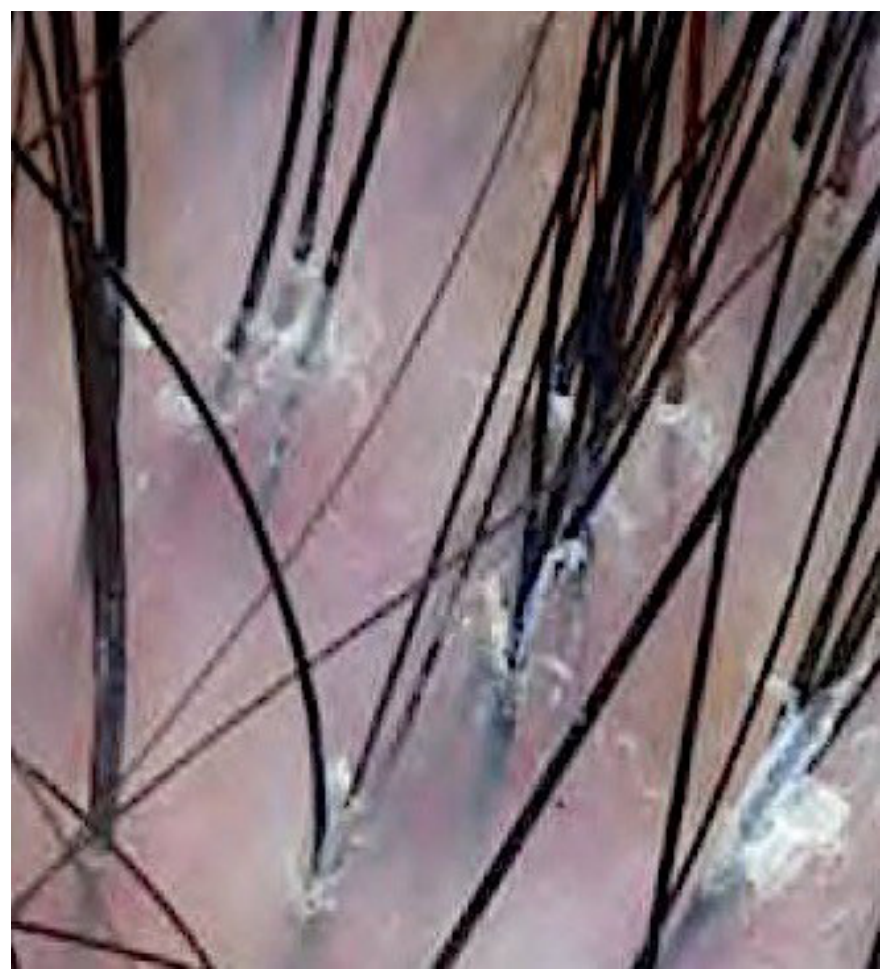

Figura 2. Tricoscopía: se observan múltiples pelos emergiendo de un orificio folicular, eritema folicular y descamación amarillenta.

sultados; sin embargo, la terapia farmacológica puede variar de acuerdo con las necesidades del paciente y la resistencia bacteriana ${ }^{(9)}$.

Actualmente, por la resistencia a los tratamientos antituberculosos, se debe pensar en otra línea de fármacos que generen menor resistencia y cubran los agentes etiológicos más frecuentes, entre ellos: clindamicina o doxiciclina en monoterapia o con tratamiento tópico coadyuvante; dapsona, como agente antimicrobiano y antiinflamatorio o isotretinoína ${ }^{(9)}$.

En casos graves o con recidivas constantes es frecuente el uso de la isotretinoína como modulador de la quimiotaxis de leucocitos, que actúa de forma directa sobre la síntesis de ARN y ejerce un efecto antiseborreico, antiqueratogénico y antiinflamatorio ${ }^{(10)}$.

Recientemente se ha planteado el uso de radioterapia localizada, con el fin de eliminar los folículos pilosos de la zona afectada, para reducir el detonante de la infección y que se eviten recidivas en las zonas inactivas y extensión de las lesiones en las zonas activas. Esta pauta terapéutica es considerada en los casos refractarios a los tratamientos tópicos, intralesionales y sistémicos ${ }^{(11,12)}$.

\section{CONCLUSIONES}

Se presentó el reporte de caso de un paciente con FD, la cual es resultado de la inflamación del folículo piloso que, secundario a su obstrucción, deja una placa de alopecia cicatricial permanente.

La relevancia del caso clínico presentado es la extensión y gravedad de las lesiones, con una evolución rápidamente progresiva y con respuesta tórpida al tratamiento inicial con terapia tópica, lo que produjo la necesidad de manejo sistémico e interdisciplinar 

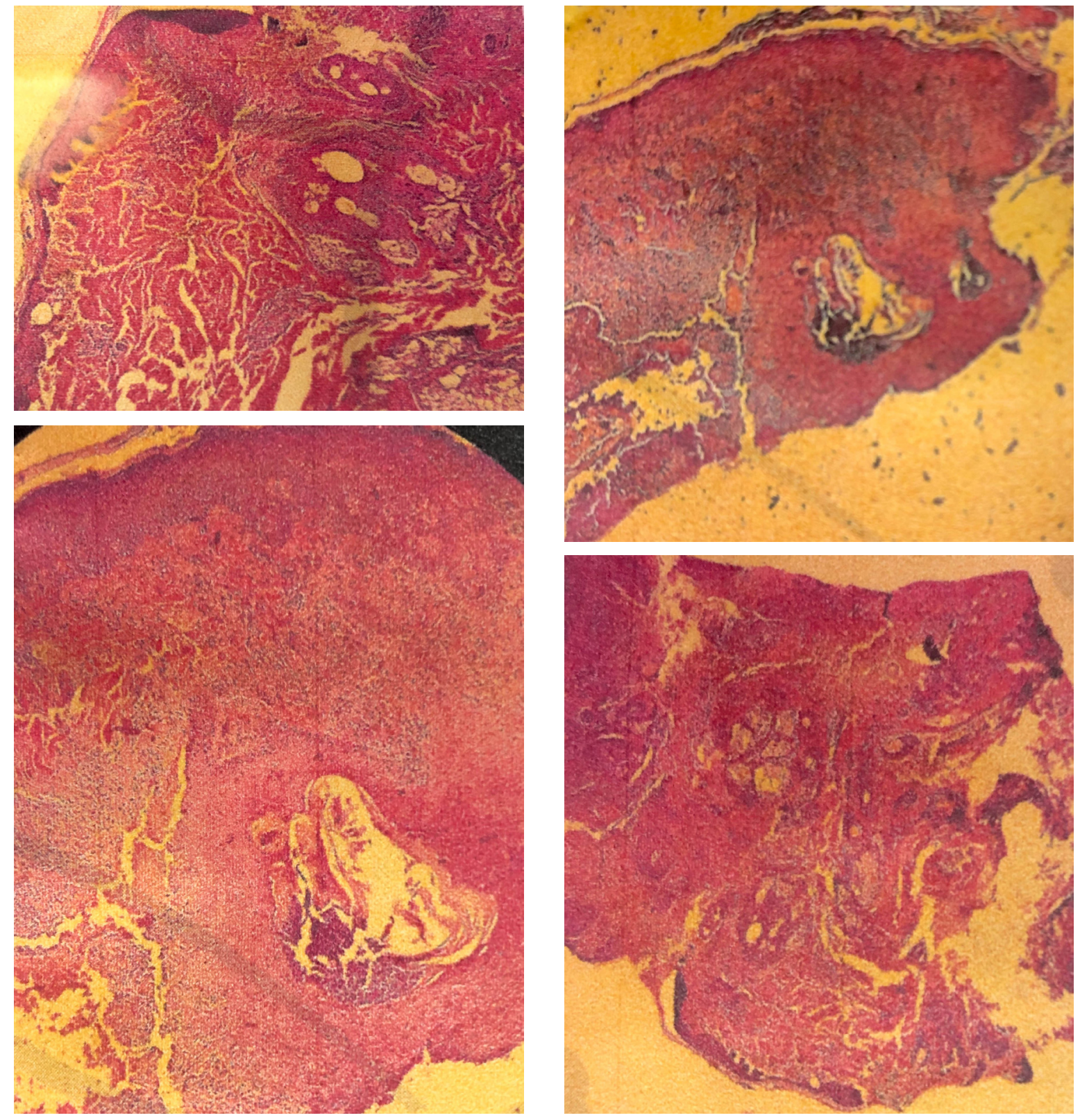

Figura 3. Biopsia de piel cabelluda, hematoxilina-eosina. Fragmentos de piel delgada con acantosis irregular, que a nivel de dermis profunda muestra quiste rodeado por epitelio escamoso, con láminas de queratina en su centro, depósitos de material amorfo eosinofílico y hemorragia reciente. 


\section{Puntos clave}

- La foliculitis decalvante (FD) es una patología caracterizada por la inflamación del folículo pilosebáceo con secreción supurativa destructiva que tras sanar deja una cicatriz atrófica.

- Las manifestaciones clínicas incluyen pústulas foliculares, con base eritematosa, dolorosas y pruriginosas, que evolucionan, dejando una placa cicatricial irregular y atrófica con lesiones pustulosas activas en la periferia, con presencia de costras mielicéricas, localizadas frecuentemente en el vértex y la región occipital de la piel cabelluda.

- El diagnóstico de FD, es principalmente clínico, y se confirma con tricoscopía y biopsia del área afectada.

- El tratamiento de la FD es complejo y se basa en la instauración de terapia antibiótica contra gérmenes gram positivos, principalmente el S. aureus, ya que es el agente etiológico más frecuente en esta entidad.

con el servicio de cirugía plástica, para realizar la resección de las áreas afectadas y, de esta manera, reducir las cicatrices y mejorar la apariencia física del paciente.

Es importante que se conozcan las manifestaciones clínicas de la FD y su abordaje diagnóstico y terapéutico, ya que por tratarse de una enfermedad progresiva y por presentar lesiones dermatológicas comunes como las pústulas puede pasar por desapercibida en los estadios iniciales, donde es más útil la implementación de la terapia farmacológica para evitar que avance a la etapa de alopecia cicatricial permanente.

El diagnóstico se hace por medio de los hallazgos clínicos y se confirma con la realización de tricoscopía y biopsia de la lesión activa.

Se recomienda hacer seguimiento de los pacientes para evaluar la aparición de recidivas y evitar la extensión de las lesiones, disminuyendo las áreas de alopecia.

\section{REFERENCIAS}

1. Otberg $\mathrm{N}$, Kang $\mathrm{H}$, Alzolibani AA, Shapiro J. Folliculitis Decalvans. Dermatol Ther. 2008;21(4):238-44. doi: 10.1111/j.1529-8019.2008.00204.X

2. Eslava García J, Matute Briceño JA. Foliculitis en penacho. Dermatol Rev Mex. 2012;56(5):132-6.

3. Chandrawansa PH, Giam YC. Folliculitis decalvans: a retrospective study in a tertiary referred centre, over five years. Singapore Med J. 2003;44(2):84-7.
4. Goldsmith LA, Katz SI, Gilchrest BA, Paller AS, Leffell D, Wolff K. Biología de los folículos pilosos. En: Fitzpatrick: Dermatología en Medicina General. 8.a edición. Madrid, España: Editorial Médica Panamericana; 2014. p. 960-1008.

5. Bernárdez C, Molina-Ruiz AM, Requena L. Histopatología de las alopecias. Parte II: alopecias cicatriciales. Actas Dermosifiliogr. 2015;106(4):260-70. doi: 10.1016/j.ad.2014.06.016

6. Rocha Fabris M, Pereira Melo C, Fernandes Melo D. Folliculitis decalvans: the use of dermatoscopy as an auxiliary tool in clinical diagnosis. An Bras Dermatol. 2013;88(5):814-6. doi: 10.1590/abd1806-4841.20132129

7. Saceda-Corralo D, Moreno-Arrones OM, Rodrigues-Barata R, Rubio-Lombraña M, Mir-Bonafé JF, Morales-Raya C, Miguel-Gómez L, Hermosa-Gelbard Á, Jaén-Olasolo P, Vañó-Galván S. Trichoscopy activity scale for folliculitis decalvans. J Eur Acad Dermatol Venereol. 2020;34(2):e55-e57. doi: 10.1111/jdv.15900

8. Miguel-Gómez L, Rodrigues-Barata AR, Molina-Ruiz A, Martorell-Calatayud A, Fernández-Crehuet $\mathrm{P}$, Grimalt $\mathrm{R}$, Barco $\mathrm{D}$, AriasSantiago S, Serrano-Falcón C, Camacho FM, Saceda-Corralo D, Jaén-Olasolo P, et al. Folliculitis decalvans: Effectiveness of therapies and prognostic factors in a multicenter series of 60 patients with long-term follow-up. J Am Acad Dermatol. 2018;79(5):878-83. doi: 10.1016/j.jaad.2018.05.1240

9. Sillani C, Bin Z, Ying Z, Zeming C, Jian Y, Xingqi Z. Effective treatment of folliculitis decalvans using selected antimicrobial agents. Int J Trichology. 2010;2(1):20-3. doi: 10.4103/0974-7753.66908 
10. Douwes KE, Landthaler M, Szeimies RM. Simultaneous occurrence of folliculitis decalvans capillitii in identical twins. Br J Dermatol. 2000;143(1):195-7. doi: 10.1046/j.1365-2133.2000.03616.x

11. Elsayad K, Kriz J, Haverkamp U, Plachouri KM, Jeskowiak A, Sunderkötter C, Eich H. Treatment of folliculitis decalvans using intensity-modulated radiation via tomotherapy. Strahlenther Onkol. 2015;191(11):883-8. doi: 10.1007/s0oo66-015-0891-6

12. Jiménez S, Uribe C, Restrepo I. Guías para el manejo de las enfermedades más frecuentes del pelo. Rev Asoc Colomb Dermatol. 2012;20(1):54-75. Disponible en: https://bit.ly/3l4fylc 